\title{
PENGARUH LATAR BELAKANG PENDIDIKAN GURU SMP/MTS TERHADAP HASIL UN BAHASA INGGRIS 2019
}

\author{
10.34005/akademika.v8i02.547
}

\author{
Safari \\ Universitas Islam As-Syafi'iyah Jakarta, Indonesia \\ Balitbang Kemendikbud, Jakarta, Indonesia \\ safari_puspendik@yahoo.com.
}

\begin{abstract}
The main purpose of this study is to answer the following question. Is there an influence on the educational background of SMP / MTs teachers on the results of the 2019 English National Examination. The population of this study is the SMP / MTs teachers who teach subjects that are UN-2019. The data in this study are in the form of test scores and teacher answers to the questionnaire in 34 provinces throughout Indonesia. The questionnaire was completed voluntarily on the last day of the UN, so the number of respondents who filled out the questionnaire was 97052 SMP / MTs teachers. The number of respondents is a sample in this study. Based on the results of the analysis of descriptive and variants of one path obtained the following results. The educational backgrounds of junior high / middle school teachers in the highest to lowest order are: (1) S-1, 88.4\%; (2) S-2, 6.3\%; (3) SMA / D1, 3.7\%; (4) D-3, 1.6\%; (5) S-3, 0.1\%. Whereas the certified teachers were only half, namely $53.2 \%$. The effect of the influence of teacher education background on the 2019 English National Examination results is proven. This means that there is a significant influence $(P<0,000)$ of teacher education background on the results of the 2019 English Language Examination (Sig. 0,000). The conclusion is that there is an influence of teacher education background on the 2019 English National Examination results.
\end{abstract}

Keywords: education, teacher, junior high school, UN, English

Abstrak :Tujuan utama studi ini adalah menjawab pertanyaan berikut. Apakah terdapat pengaruh latar belakang pendidikan guru SMP/MTs terhadap hasil UN Bahasa Inggris 2019. Populasi penelitian ini adalah guru SMP/MTs yang mengajar mata pelajaran yang di-UN-kan tahun 2019. Data dalam penelitian ini berbentuk skor tes dan jawaban guru terhadap kuesioner di 34 provinsi di seluruh Indonesia. Pengisian kuesioner dilakukan secara sukarela di hari terakhir UN, sehingga jumlah responden yang mengisi kuesioner adalah 97052 guru SMP/MTs. Jumlah responden ini merupakan sampel dalam penelitian ini. Berdasarkan hasil analisis deskriptif dan varian satu jalur diperoleh hasil seperti berikut. Latar belakang pendidikan guru SMP/MTs dengan urutan tertinggi hingga terendah adalah: (1) S-1, 88,4\%; (2) S-2, 6,3\%; (3) SMA/D1, 3,7\%; (4) D-3, 1,6\%; (5) S-3, 0,1\%. Adapun guru yang sudah tersertifikasai adalah baru separuh yaitu $53,2 \%$. Pengaruh pengaruh latar belakang pendidikan guru terhadap hasil UN Bahasa Inggris 2019 adalah terbukti. Artinya terdapat pengaruh yang signifikan $(P<0,000)$ latar belakang pendidikan guru terhadap hasil UN Bahasa Inggris 2019 (Sig. 0,000). Kesimpulannya adalah terdapat pengaruh latar belakang pendidikan guru terhadap hasil UN Bahasa Inggris 2019.

Kata Kunci: Pendidikan, Guru, SMP, UN, Bahasa Inggris

105|Akademika Jurnal Teknologi Pendidikan Vol.8 No. 21019 


\section{PENDAHULUAN}

Dalam rangka memperingati Hari Guru di Indonesia yang diperingati setiap tanggal 25 November, penulis sengaja memberikan renungan hasil penelitian yang penulis tulis dalam jurnal ilmiah ini.Tujuan utamanya adalah untuk meningkatkan mutu pendidikan kita di Indonesia melalui perbaikan guru dalam beragam aspeknya agar mampu bersaing di tingkat internasional. Hal ini sangat penting karena pendidikan sangat menentukan kemajuan dan mutu bangsa. Kualitas pendidikan memengaruhi kualitas bangsa. Bangsa yang maju memiliki pendidikan yang baik. Pendidikan yang baik diperoleh dari kualitas guru yang baik. Jadi, guru merupakan faktor kunci mutu pendidikan dan kemajuan sebuah bangsa, setelah orang tua dan pemerintah. Undang-Undang Republik Indonesia Nomor 14 Tahun 2005 Tentang Guru Dan Dosen, Pasal 8 berisi bahwa guru wajib memiliki kualifikasi akademik, kompetensi, sertifikat pendidikan, sehat jasmani dan rohani serta memiliki kemampuan untuk mewujudkan tujuan pendidikan nasional. Pasal 9 persyaratan menjadi guru minimal berijazah sarjana (S1) atau diploma empat (D4). Dengan tidak membedakan apakah itu guru SD, SMP, atau guru pada jenjang pendidikan menengah.

Berdasarkan data UNESCO dalam Global Education Monitoring (GEM) Report 2016, pendidikan di Indonesia menempati peringkat ke-10 dari 14 negara berkembang dan kualitas guru menempati ukuran ke-14 dari 14 negara berkembang di dunia, Pak/Bu. Jumlah guru mengalami peningkatan sebanyak $382 \%$ dari 1999/2000 menjadi sebanyak 3 juta orang lebih, sedangkan peningkatan jumlah peserta didik hanya $17 \%$. Dari 3.9 juta guru yang ada, masih terdapat $25 \%$ guru yang belum memenuhi syarat kualifikasi akademik dan $52 \%$ di antaranya belum memiliki sertifikat profesi. Dengan jumlah guru yang banyak, diharapkan kegiatan belajar yang optimal dapat tercapai. Sayangnya, meningkatnya kuantitas guru tidak sejalan dengan kualitasnya.

Persoalan rendahnya kualitas pendidikan di Indonesia tentu tidak bisa dijawab dengan cara mengubah kurikulum. Atau, bahkan mengganti menteri atau dirjen. Kualitas pendidikan hanya bisa dijawab oleh kualitas guru. Guru yang profesional, guru yang berkualitas adalah jaminannya. Tanpa perbaikan kualitas guru maka kualitas pendidikan akan tetap "jauh panggang dari api", akan tidak memadai. Persoalan guru memang tidak sederhana. Membahas kompetensi guru, prinsip dasarnya adalah memetakan faktor-faktor yang menyebabkan rendahnya kompetensi guru. Dalam konteks ini, setidaknya dapat diduga ada empat penyebab rendahnya kompetensi guru. Pertama, ketidaksesuaian disiplin ilmu dengan bidang ajar. Masih banyak guru di sekolah yang mengajar mata pelajaran yang bukan bidang studi yang dipelajarinya. Hal ini terjadi karena persoalan kurangnya guru pada bidang studi tertentu. Kedua, kualifikasi guru yang belum setara sarjana. Konsekuensinya, standar keilmuan yang dimiliki guru menjadi tidak memadai untuk mengajarkan bidang studi yang menjadi tugasnya. Bahkan tidak sedikit guru yang sarjana, namun tidak berlatar belakang sarjana pendidikan sehingga "bermasalah" 
dalam aspek pedagogik. Ketiga, program peningkatan keprofesian berkelanjutan (PKB) guru yang rendah. Masih banyak guru yang "tidak mau" mengembangkan diri untuk menambah pengetahuan dan kompetensinya dalam mengajar. Guru tidak mau menulis, tidak membuat publikasi ilmiah, atau tidak inovatif dalam kegiatan belajar. Guru merasa hanya cukup mengajar. Keempat, rekruitmen guru yang tidak efektif. Karena masih banyak calon guru yang direkrut tidak melalui mekanisme yang profesional, tidak mengikuti sistem rekruitmen yang dipersyaratkan. Kondisi ini makin menjadikan kompetensi guru semakin rendah.

Pertanyaan mengapa orang memilih mengajar sebagai karier menarik dan kompleks. Ini juga merupakan pertanyaan yang perlu perhatian segera. Di Inggris, seperti di seluruh dunia, rekruitmen dan retensi guru tetap menjadi masalah yang membakar dan satu di garis depan tujuan pembangunan berkelanjutan global (SDG) dari Organisasi Pendidikan, (La Velle,2019). Para calon guru yang berkomitmen pada program residensi guru perkotaan yang berorientasi keadilan sosial mengartikulasikan dan mencerminkan mengapa mereka ingin menjadi guru di sekolah negeri yang sangat membutuhkan dan apa yang mereka harapkan dari pengajaran untuk memastikan apa yang mereka harapkan akan lakukan, (Lee dkk.,2019). Faktor pendukung pengembangan kompetensi guru adalah: pertama, keberadaan guru yang telah menjadi instruktur nasional pelaksanaan Kurikulum 2013. Kedua, guru memiliki motivasi yang tinggi untuk mengikuti program pengembangan kurikulum ini. Ketiga, sekolah menyediakan anggaran untuk pelaksanaan program pengembangan. Faktor penghambatnya adalah; pertama, peserta program tidak mendapatkan gaji. Kedua, kendala teknis seperti proyektor rusak. Ketiga, perencanaan waktu pelaksanaan agar tidak mengganggu kegiatan pembelajaran di sekolah. (Najib dan Pardjono,2019). Supervisi akademik dapat membantu guru untuk mempelajari dan memahami tugas dan perannya sebagai seorang pendidik. (Lalupanda,2019). Gambar 1 menunjukkan persentase pendidikan guru setiap tahunnya meningkat, (Rachmawati dkk.,2017).

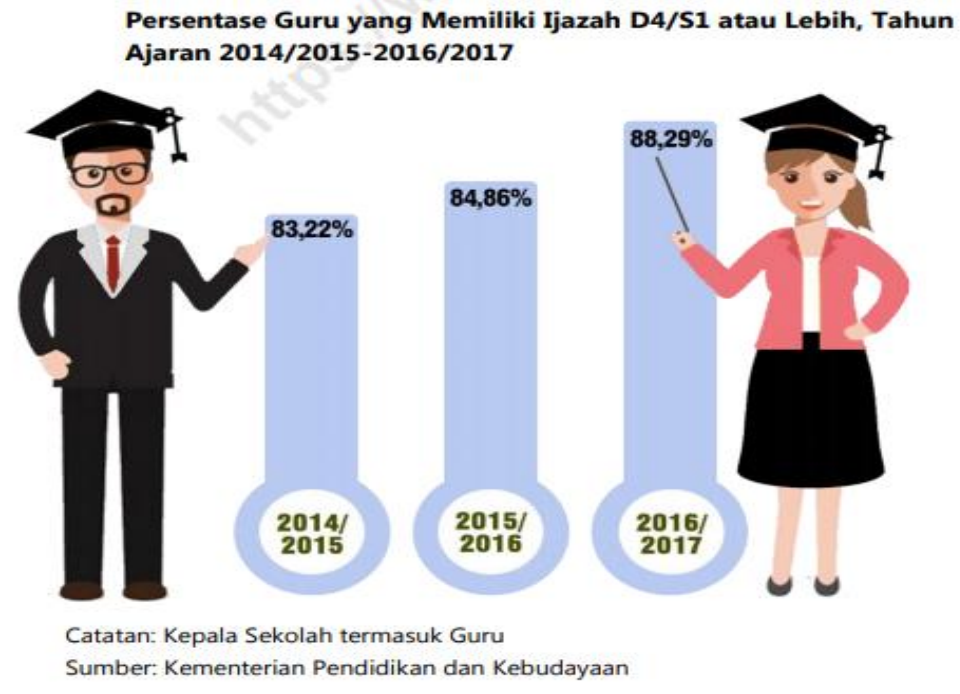

Gambar 1. Peningkatan Pendidikan Guru 
Hasil penelitian Fadhillah dkk. (2019) menunjukkan bahwa kompetensi guru yang mengajar mata pelajaran Bahasa Inggris rendah berdasarkan berpikir sistem (system thinking) sehingga masalah mendasar tersebut dapat menjadi daya ungkit dalam penyelesaian masalah rendahnya kompetensi mutu dan kompetensi guru dalam mengajar mata pelajaran Bahasa Inggris. Hal ini terjadi karena guru Bahasa Inggris dituntut memiliki kemampuan yang lengkap dan kinerja yang baik dalam pembelajaran. (Sarifudin, 2019). Namun Mahyuddin dan Yanti (2018) telah mengadakan penelitian yang sama, tetapi hasilnya adalah tidak terdapat perbedaan yang signifikan kinerja mengajar guru yang ditinjau dari latar belakang pendidikan, (Mahyuddin dan Yanti,2018). Sebagai contoh kemampuan guru SMP Negeri di Kecamatan Depok, Kabupaten Sleman dalam menyusun RPP, yang terdiri dari berbagai aspek adalah berkategori "Sangat Baik" (100\%). (Angkawati,2019).

Dalam pelaksanaannya profesi guru masih terkendala: (1) kualitas Lembaga Pendidikan Tenaga Kependidikan, (2) kualifikasi calon peserta didik, dan (3) penyerapan lulusan. Perlu adanya perbaikan dari sisi tata kelola dan regulasi guna meningkatkan efektivitas penyelenggaraan pendidikan profesi guru, (Arifa dan Prayitno,2019). Problematika guru dalam meningkatkan perilaku sosial siswa di antaranya: kurangnya minat dan kesadaran siswa dalam melaksanakan tata tertib sekolah, kurangnya pengembangan sarana dan prasarana sekolah, lingkungan pergaulan yang kurang baik, sehingga ada sebagian dari siswa yang perilakunya kurang baik. Upaya dalam mengatasi problematika yang dialami guru di antaranya adalah: membangun kebiasaan perilaku kesosialan yang positif, melengkapi sarana dan prasarana yang kurang, membangun keteladanan, menjalin komunikasi dengan berbagai pihak. (Shofiyuddin,2019).

Dalam mengatasi problematika seperti itu, ada tiga manfaat yang diperoleh, yaitu: advokasi perubahan, berbagi bersama, dan pengurangan tanggung jawab, (Lindqvist,2019). Ketiga manfaat itu merupakan bagian dari efektivitas pengembangan profesional guru, karena kegiatan ini sangat mendukung pembelajaran guru dan berdampak positif yang terukur pada kualitas pengajaran dan moral guru, (Gore dkk.2019). Berkaitan dengan kualitas guru, hasil Uji Kompetensi Guru (UKG) beberapa tahun terakhir menunjukkan kompetensi guru Indonesia rendah. Peringkat rendah Indonesia dalam beberapa pemeringkatan dunia tentang kemampuan siswa dalam bidang Membaca, Matematika, dan Sains juga secara tidak langsung menunjukkan kelemahan kompetensi guru. Rata-rata nasional hasil UKG 2015 bidang pedagogik dan profesional adalah 53,02 . Tanda lain guru tidak kompeten adalah tidak bisa menggunakan komputer, metode mengajarnya ceramah, tidak bisa menerapkan metode mengajar yang aktif dan menyenangkan, tidak bisa memanfaatkan dan mengolah informasi dari internet, tidak kontekstual, dan seterusnya. (Jilan, 2018).

Dari berbagai uraian di atas, permasalahan dalam penelitian ini adalah apakah terdapat pengaruh latar belakang pendidikan guru SMP/MTs terhadap 
hasil UN Bahasa Inggris 2019. Oleh karena itu, tujuan penelitian ini adalah untuk mengetahui apakah terdapat pengaruh latar belakang pendidikan guru SMP/MTs terhadap hasil UN Bahasa Inggris 2019.

\section{METODE}

Metode penelitian yang dipergunakan adalah metode eksploratif. Dasar penggunaan metode ini adalah disesuaikan dengan tujuan utama penelitian ini di antaranya adalah untuk memperoleh fakta-fakta dari gejala-gejala yang ada dan mencari keterangan-keterangan secara faktual berdasarkan data penelitian ini. Populasi penelitian ini adalah guru SMP/MTs yang mengajarkan materi yang diUN-kan tahun 2019. Data dalam penelitian ini berbentuk skor tes dan jawaban guru terhadap kuesioner di 34 provinsi di seluruh Indonesia. Pengisian kuesioner dilakukan secara sukarela di hari terakhir UN. Jumlah responden ini merupakan sampel dalam penelitian ini. Jumlah responden adalah 97052 guru SMP/MTs yang terdiri atas SMPN/MTsN 49154 guru dan SMPS/MTsS 47802 guru.

Metode analisis yang dipergunakan dalam penelitian ini adalah deskriptif dan analisis varian satu jalur. Keduanya dipergunakan untuk menghitung pengaruh latar belakang pendidikan guru SMP/MTs terhadap hasil UN Bahasa Inggris 2019. Agar hasil analisis penelitian ini dapat diperoleh secara akurat, maka semua data dalam penelitian ini diolah atau dianalisis dengan mempergunakan program SPSS 22.00 dan Mplus versi 8.2.

\section{HASIL}

Berdasarkan persentase jumlah guru yang telah mengisi kuesioner 97052 guru SMP/MTs adalah seperti pada Tabel 1 .

Tabel 1. Persentase Latar Belakang Pendidikan Guru

\begin{tabular}{llrrrr}
\hline & & & & \multicolumn{2}{c}{$\begin{array}{c}\text { Cumulative } \\
\text { Percent }\end{array}$} \\
\hline Valid & Frequency & Percent & Valid Percent & 3,7 & 3,7 \\
& SMA/D1 & 3569 & 3,7 & 1,6 & 5,3 \\
& D3 & 1551 & 1,6 & 88,4 & 93,7 \\
S-1 & 85794 & 88,4 & 6,3 & 99,9 \\
S-2 & 6076 & 6,3 &, 1 & 100,0 \\
S-3 & 62 &, 1 & 100,0 & \\
Total & 97052 & 100,0 & &
\end{tabular}


Tabel 1 menginformasikan bahwa latar belakang pendidikan guru dengan urutan peningkatan tertinggi hingga terendah adalah: (1) S-1, 88,4\%; (2) S-2, 6,3\%; (3) SMA/D1, 3,7\%; (4) D-3, 1,6\%; (5) S-3, 0,1\%. Gambar 2 latar belakang pendidikan guru. Tabel 2 menunjukkan bahwa guru yang sudah sertifikasai adalah baru separuh yaitu $53,2 \%$.

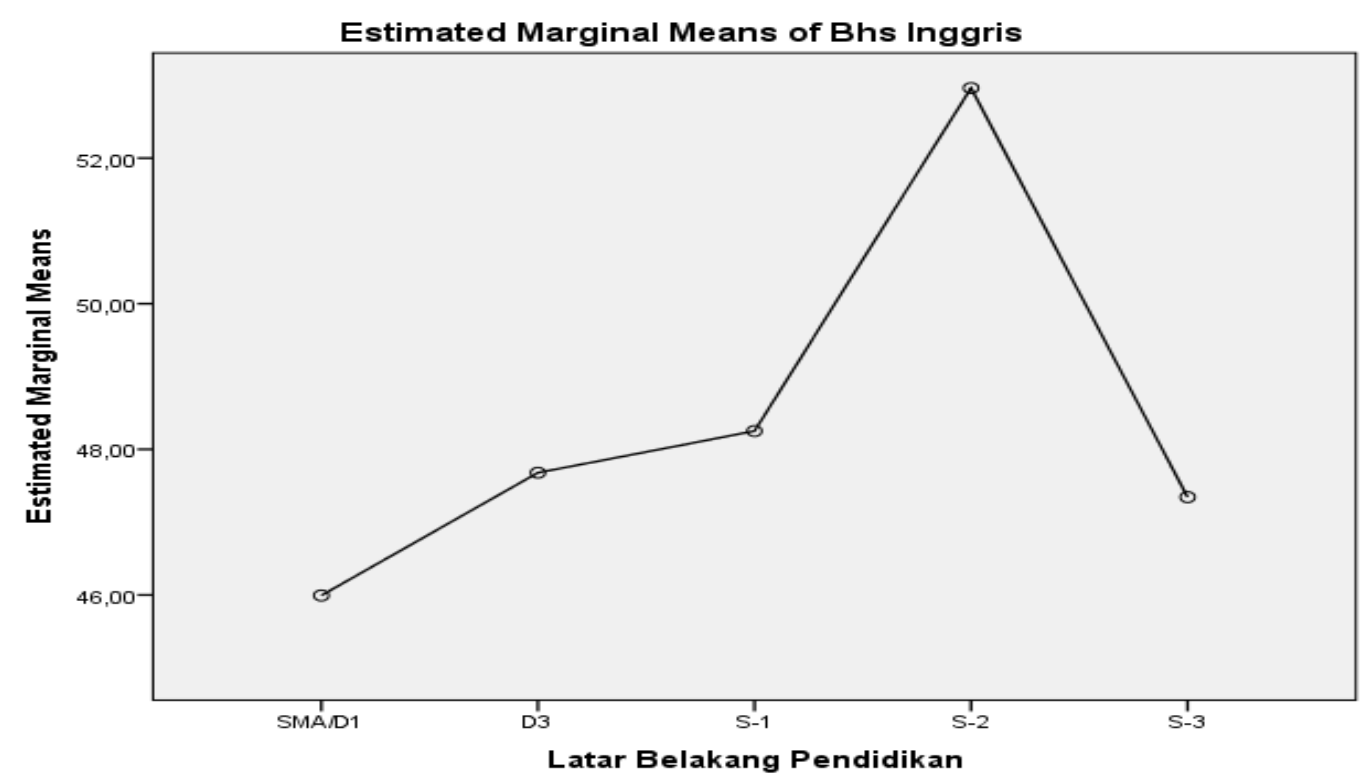

Gambar 2. Latar Belakang Pendidikan Guru

Tabel 2. Sertifikasi

\begin{tabular}{llrrrr}
\hline & & & & \multicolumn{2}{c}{ Cumulative } \\
& & Frequency & Percent & Valid Percent & Percent \\
\hline \multirow{2}{*}{ Valid } & Sudah Sertifikasi & 51647 & 53,2 & 53,2 & 53,2 \\
& Belum Sertifikasi & 45405 & 46,8 & 46,8 & 100,0 \\
& & 97052 & 100,0 & 100,0 & \\
\hline
\end{tabular}

Tabel 3. Tes Anova

\begin{tabular}{lrrrrr}
\hline Source & $\begin{array}{l}\text { Type III Sum } \\
\text { of Squares }\end{array}$ & df & Mean Square & \multicolumn{1}{c}{ F } & Sig. \\
\hline Corrected Model & $149646,167^{\mathrm{a}}$ & 4 & 37411,542 & 340,059 &, 000 \\
Intercept & 3405341,579 & 1 & 3405341,579 & 30953,445 &, 000 \\
Pendidikan & 149646,167 & 4 & 37411,542 & 340,059 &, 000 \\
Error & 10676510,346 & 97046 & 110,015 & & \\
Total & 238673685,193 & 97051 & & & \\
Corrected Total & 10826156,513 & 97050 & & & \\
\hline
\end{tabular}

a. R Squared $=, 014$ (Adjusted R Squared $=, 014$ ) 
Tabel 3 menunjukkan bahwa pengaruh latar belakang pendidikan guru terhadap hasil UN Bahasa Inggris 2019 adalah terbukti. Artinya terdapat pengaruh yang signifikan $(P<0,000)$ latar belakang pendidikan guru terhadap hasil UN Bahasa Inggris 2019, (Sig. 0,000).

Adapun hubungan keseluruhan variabel terlihat pada Gambar 3 berikut, yaitu hasil analisis dengan program Mplus versi 8.2.

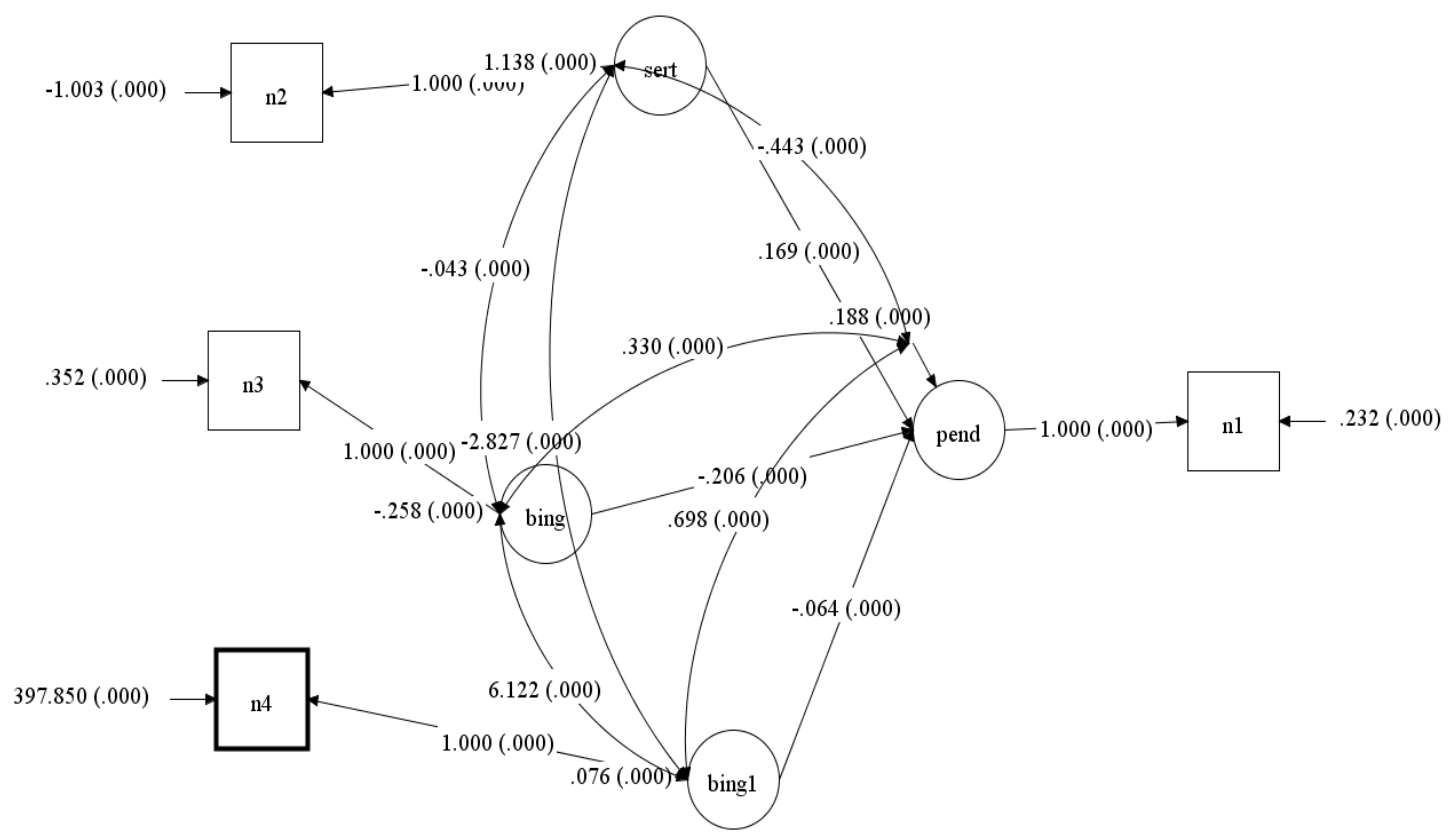

Gambar 3: Hubungan Antar Variabel

Berdasarkan Gambar 3 hubungan latar belakang pendidikan guru SMP dengan variabel lainnya mulai dari yang termudah sampai tersulit terdapat pada: (1) hubungan dengan nilai UN mata pelajaran Bahasa Inggris (loading faktornya $0,206)$; (2) hubungan dengan tingkat kriteria perolehan siswa (loading faktornya $0,064)$; dan (3) sertifikasi guru (loading faktornya 0,169 ).

\section{PEMBAHASAN}

Kesimpulan penelitian ini adalah pengaruh latar belakang pendidikan guru terhadap hasil UN Bahasa Inggris 2019 adalah terbukti. Artinya terdapat pengaruh yang signifikan $(P<0,000)$ latar belakang pendidikan guru terhadap hasil UN Bahasa Inggris 2019, (Sig. 0,000). Namun bila diperhatikan persentase sumbangannya secara rinci terlihat pada Tabel 4. sumbangan terbesar terhadap mata pelajaran Bahasa Inggris yang di-UN-kan adalah guru yang berlatar belakang pendidikan S-1 dan S-2, baik untuk siswa yang mendapatkan nilai UN "Sangat baik", "Baik", 
"Cukup", maupun "Kurang". Sumbangan kedua, ketiga, dan keempat adalah guru yang berlatar belakang SMA/D1, D4, dan S-3.

Tabel 4.

Persentase Sumbangan Terhadap Nilai UN Mata Pelajaran Bahasa Inggris

\begin{tabular}{|c|c|c|c|c|c|c|c|}
\hline \multirow[b]{3}{*}{ Kriteria } & & \multicolumn{5}{|c|}{ Latar Belakang Pendidikan } & \multirow[t]{3}{*}{ Total } \\
\hline & & \multicolumn{5}{|l|}{ SMA/ } & \\
\hline & & D1 & D3 & S-1 & S-2 & S-3 & \\
\hline \multirow[t]{2}{*}{ Sangat Baik } & Count & 30 & 14 & 1224 & 210 & 1 & 1479 \\
\hline & $\%$ of Total & $0,0 \%$ & $0,0 \%$ & $1,3 \%$ & $0,2 \%$ & $0,0 \%$ & $1,5 \%$ \\
\hline \multirow[t]{2}{*}{ Baik } & Count & 71 & 67 & 3300 & 516 & 1 & 3955 \\
\hline & $\%$ of Total & $0,1 \%$ & $0,1 \%$ & $3,4 \%$ & $0,5 \%$ & $0,0 \%$ & $4,1 \%$ \\
\hline \multirow[t]{2}{*}{ Cukup } & Count & 276 & 167 & 9870 & 1112 & 8 & 11433 \\
\hline & $\%$ of Total & $0,3 \%$ & $0,2 \%$ & $10,2 \%$ & $1,1 \%$ & $0,0 \%$ & $11,8 \%$ \\
\hline \multirow[t]{2}{*}{ Kurang } & Count & 3192 & 1303 & 71400 & 4238 & 52 & 80185 \\
\hline & $\%$ of Total & $3,3 \%$ & $1,3 \%$ & $73,6 \%$ & $4,4 \%$ & $0,1 \%$ & $82,6 \%$ \\
\hline \multirow[t]{2}{*}{ Total } & Count & 3569 & 1551 & 85794 & 6076 & 62 & 97052 \\
\hline & $\%$ of Total & $3,7 \%$ & $1,6 \%$ & $88,4 \%$ & $6,3 \%$ & $0,1 \%$ & $100,0 \%$ \\
\hline
\end{tabular}

Tabel 4. memberikan informasi bahwa guru yang berlatar belakang pendidikan S-1 dan S-2, memberikan sumbangan tertinggi untuk siswa yang mendapatkan nilai UN Bahasa Inggris "Sangat baik", "Baik", dan "Cukup". Hasil penelitian ini sesuai dengan tuntutan Undang-Undang Republik Indonesia Nomor 14 Tahun 2005 Tentang Guru Dan Dosen, Pasal 8 berisi bahwa guru wajib memiliki kualifikasi akademik, kompetensi, sertifikat pendidikan, sehat jasmani dan rohani serta memiliki kemampuan untuk mewujudkan tujuan pendidikan nasional. Pasal 9 persyaratan menjadi guru minimal berijazah sarjana (S1) atau diploma empat (D4). Dengan tidak membedakan apakah itu guru SD, SMP, atau guru pada jenjang pendidikan menengah. Hal ini menunjukkan bahwa pendidikan sangat menentukan kemajuan dan mutu sebuah bangsa. Kualitas pendidikan memengaruhi kualitas bangsa. Bangsa yang maju memiliki pendidikan yang baik. Pendidikan yang baik diperoleh dari kualitas guru yang baik. Guru merupakan faktor kunci mutu pendidikan dan kemajuan sebuah bangsa. Bila diperhatikan Gambar 4 dilihat dari jenjang pendidikan, guru SD layak mengajar memiliki peningkatan paling besar dibandingkan lainnya. Dari 66,60 persen pada 2012/2013 naik menjadi 84,21 persen pada 2016/2017. Sayangnya, angka tersebut masih lebih rendah dibandingkan 
jenjang pendidikan lain. Semakin tinggi jenjang pendidikan semakin besar persentase guru layak mengajar.

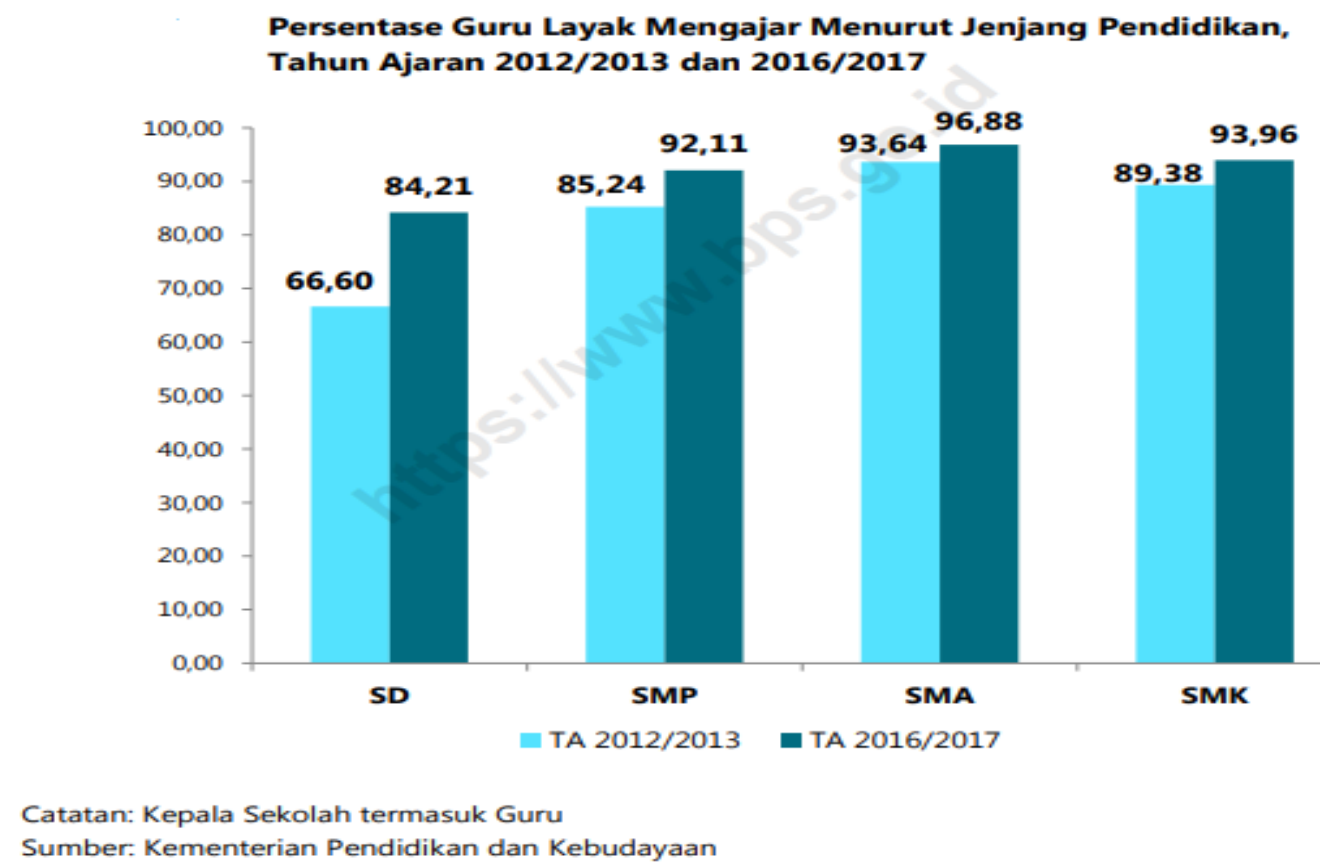

Gambar 4. Peningkatan Pendidikan Guru

Dampak guru yang tidak efektif pada kenyataannya hanya membuat peningkatan motivasi belajar siswa berkurang. Akibatnya kemalasan, cuek dalam mengerjakan tugas sehingga timbulnya rasa ketidaknyamanan di dalam kelas maunya keluar karena metode yang membuat dia bosan dan ada juga yang timbul dibenak siswa kata-kata samaran yang ia berikan kepada guru tersebut yang terkesan menurut mereka lucu sebagai gurauan tetapi sebenarnya itu masuk pada karakter yang tidak baik. Dari situlah timbul rasa bosan kepada siswa-siswinya saat berlangsung proses mata pelajaran yang diajarkan guru tersebut. Karena metode atau cara pengajarannya yang cenderung hanya memberikan tugas atau mencatat saja atau juga metode pengajarannya menggunakan metode ceramah lalu siswasiswinya ditugaskan mencatat materi yang guru berikan tersebut. Tanpa memperhatikan psikologi anak yang cenderung mudah bosan karena metode yang di gunakan tidak menarik dan membosankan.

Dalam konteks ini, setidaknya dapat diduga ada empat penyebab rendahnya kompetensi guru, (Yunus, 2019). Pertama, ketidaksesuaian disiplin ilmu dengan bidang ajar (miss-match). Masih banyak guru di sekolah yang mengajar mata pelajaran yang bukan bidang studi yang dipelajarinya. Hal ini terjadi karena persoalan kurangnya guru pada bidang studi tertentu. Kedua, kualifikasi guru yang belum setara sarjana. Konsekuensinya, standar keilmuan yang dimiliki guru menjadi tidak memadai untuk mengajarkan bidang studi yang menjadi tugasnya. Bahkan tidak sedikit guru yang sarjana, namun tidak berlatar belakang sarjana pendidikan sehingga "bermasalah" dalam aspek pedagogik. Ketiga, program peningkatan keprofesian berkelanjutan (PKB) guru yang rendah. Masih banyak guru yang "tidak 
mau" mengembangkan diri untuk menambah pengetahuan dan kompetensinya dalam mengajar. Guru tidak mau menulis, tidak membuat publikasi ilmiah, atau tidak inovatif dalam kegiatan belajar. Guru merasa hanya cukup mengajar. Keempat, rekruitmen guru yang tidak efektif. Karena masih banyak calon guru yang direkrut tidak melalui mekanisme yang professional, tidak mengikuti sistem rekruitmen yang dipersyarakatkan. Kondisi ini makin menjadikan kompetensi guru semakin rendah.

\section{KESIMPULAN}

Berdasarkan semua uraian di atas, hasil penelitian dapat disimpulkan dengan adanya temuan-temuan dan saran seperti berikut ini. Latar belakang pendidikan guru dengan urutan peningkatan tertinggi hingga terendah adalah: (1) S-1, 88,4\%; (2) S2, 6,3\%; (3) SMA/D1, 3,7\%; (4) D-3, 1,6\%; (5) S-3, 0,1\%. Adapun guru yang sudah tersertifikasai adalah baru separuh yaitu $53,2 \%$. Pengaruh latar belakang pendidikan guru terhadap hasil UN Bahasa Inggris 2019 adalah terbukti. Artinya terdapat pengaruh yang signifikan $(P<0,000)$ latar belakang pendidikan guru terhadap hasil UN Bahasa Inggris 2019, (Sig. 0,000).

\section{SARAN}

Berdasarkan hasil penelitian di atas, ada saran penting seperti berikut ini. Walaupun UN tidak menjadi penentu kelulusan siswa, UN masih merupakan satu-satunya alat ukur standar nasional yang ada di Indonesia untuk mengukur mutu pendidikan dan sangat diminati siswa khususnya mata pelajaran Bahasa Inggris. Oleh karena itu, ada beberapa saran berikut. UNBK bukan menjadi penyebab turunnya nilai rata-rata Bahasa Inggris di beberapa sekolah, namun dalam meningkatkan mutu UN tidak terlepas dari kerja keras para peserta Ujian dan seluruh stakeholder dalam bidang pendidikan terutama guru Bahasa Inggris yang merupakan aktor utama dalam pelaksanaan proses belajar mengajar di kelas. Demi meningkatkan mutu UN Bahasa Inggris diharapkan para pendidik memaksimalkan persiapan dalam pelaksanaan UN, baik melalui kegiatan pendalaman materi terhadap peserta ujian, melakukan simulasi-simulasi agar peserta ujian tidak canggung dalam melaksanakan UNBK serta menfasilitasi kebutuhan persiapan pelaksanaan Ujian Nasional. Hal ini juga tentu tidak terlepas dari peran pemerintah untuk mendukung segala aspek dalam persiapan dan pelaksanaan Ujian Nasional agar terlaksana dengan baik. Pelaksanaan UNBK harus terus dilaksanakan untuk meningkatkan kualitas pendidikan dan pencapaian hasil belajar siswa yang jujur dan mandiri, serta latar belakang pendidikan guru yang sesuai dengan Undang-Undang Republik Indonesia Nomor 14 Tahun 2005 Tentang Guru Dan Dosen, Pasal 8 berisi bahwa guru wajib memiliki kualifikasi akademik, kompetensi, sertifikat pendidikan, sehat jasmani dan rohani serta memiliki kemampuan untuk mewujudkan tujuan pendidikan nasional. Pasal 9 persyaratan menjadi guru minimal berijazah sarjana (S-1) atau diploma empat (D-4). Dengan tidak membedakan apakah itu guru SD, SMP, atau guru pada jenjang pendidikan menengah. 


\section{SELAMAT MEMPERINGATI HARI GURU 25 NOVEMBER 2019.}

Ucapan Terima Kasih

Penulis mengucapkan banyak terima kasih kepada Pusat Penilaian Pendidikan (Puspendik) yang telah mendokumentasikan data UN setiap tahun yang datanya dipergunakan untuk penelitian ini. Di samping itu, penulis mengucapkan terima kasih kepada teman-teman di Puspendik yang telah memberikan masukan, saran, dan komentar, sehingga terwujudnya tulisan ini.

\section{DAFTAR PUSTAKA}

Angkawati, GR. (2019). Kemampuan Guru PJOK SMP Negeri Di Kecamatan Depok, Kabupaten Sleman Dalam Menyusun Rencana Pelaksanaan Pembelajaran PJOK. Skripsi. Pendidikan Jasmani Kesehatan dan Rekreasi Fakultas IImu Keolahragaan Universitas Negeri Yogyakarta.

Arifa, FN dan Prayitno, US. (2019). Peningkatan Kualitas Pendidikan: Program Pendidikan Profesi Guru Prajabatan dalam Pemenuhan Kebutuhan Guru Profesional di Indonesia. Aspirasi: Jurnal Masalah-Masalah Sosial | Volume 10, No. 1 Juni 2019 ISSN: 2086-6305 (print) ISSN: 2614-5863 (electronic) DOI: https://doi.org/10.22212/aspirasi.v7i1.1084 link online: http://jurnal.dpr.go.id/index.php/aspirasi/index.

Fadhillah; Rugaiyah; Fuad, N.; dan Julia, P. (2019). Upaya Peningkatan Kompetensi Guru Berdasarkan System Thingking. Jurnal Akuntabilitas Manajemen Pendidikan Volume 7, No 1, April 2019 (1-14) Online: http://journal.uny.ac.id/index.php/jamp.

Gore, J.; Lloyd, A.; Smith, M.; Bowe, J.; Ellis, H.; and Lubans, D. (2019). Effects of professional development on the quality of teaching: Results from a randomised controlled trial of Quality Teaching Rounds. Teaching and Teacher Education, Volume 68, November 2017, Pages 99-113.

Jilan, B. (2018). Permasalahan Guru di Indonesia. UIN Syarif Hidayatullah Jakarta. https://www.uinjkt.ac.id/id/permasalahan-guru-di-indonesia/

Lalupanda, EM. (2019). Implementasi Supervisi Akademik Untuk Meningkatkan Mutu Guru. Jurnal Akuntabilitas Manajemen Pendidikan Volume 7, No 1, April 2019 (62-72) Online: http://journal.uny.ac.id/index.php/jamp.

La Velle, L. (2019). Motivation and provision in teacher education: context, culture and capacity. Journal of Education for Teaching. International research and pedagogy, Vol. 45, Issue 5, 2019. Pages 491-493 https://doi.org/10.1080/02607476.2019.1675356. 
Lee, CC; Akin, S; and Goodwin, AL. (2019). Teacher candidates' intentions to teach: implications for recruiting and retaining teachers in urban schools. . Journal Of Education For Teaching. International Research And Pedagogy, Vol. 45, Issue $\quad 5, \quad 2019.2$ Pages https://doi.org/10.1080/02607476.2019.1675356.

Lindqvist, H. (2019). Strategies to cope with emotionally challenging situations in teacher education. Journal of Education for Teaching. International research and pedagogy, Vol. 45, Issue 5, 2019. Pages 540-552 https://doi.org/10.1080/02607476.2019.1675356.

Mahyuddin, N. dan Yanti, S. (2018). Kinerja Mengajar Guru Pendidikan Anak Usia Dini Dan Latar Belakang Pendidikan. Early Childhood Education Journal of Indonesia, IJECES 1 (2) (2018).

Najib, KH. dan Pardjono. (2019). Manajemen Pengembangan Kompetensi Guru Untuk Implementasi Kurikulum 2013 Di Sma Negeri Pilot Project Yogyakarta. Jurnal Akuntabilitas Manajemen Pendidikan, Volume 7, No 1, April 2019 (5061) Online: http://journal.uny.ac.id/index.php/jamp.

Sarifudin, A. (2019). Peningkatan Kinerja Guru Dalam Implementasi Penilaian Sistem SKS Melalui Supervisi Akademik Pengawas Sekolah. Edukasi Islami: Jurnal Pendidikan Islam, VOL: 08/NO: 02 Agustus 2019 P-ISSN: 2614-4018 DOI : 10.30868/ei.v812.539. E-ISSN: 2614-8846.

Shofiyuddin, A. (2019). Problematika Guru Pai Dalam Membina Perilaku Sosial Siswa. Darajat : Jurnal PAl, Volume 2 Nomor 1 Maret 2019.

Rachmawati, Y.; Riana, N.; Silviliana, M.; dan Sulistyowati, R. (2017). Potret Pendidikan Indonesia: Statistik Pendidikan 2017. Badan Pusat Statistik.

Yunus, S. (2019). Kenali 4 Penyebab Rendahnya Kompetensi Guru. https://www.indonesiana.id/read/119880/empat-sebab-rendahnya-kompetensi-guru. 